\title{
Devic's Neuromyelitis Optica: A Case with Mitochondrial DNA Mutations
}

\author{
Neşe Çelebisoy Onder Akyurekli Aslı Copur \\ Ege University Medical School, Department of Neurology, Bornova, İzmir, Turkey
}

Dear Sir,

Devic's neuromyelitis optica (DNO) is an uncommon but severe form of demyelinating disease characterized by acute attacks of optic neuritis $(\mathrm{ON})$ and myelitis [1]. The term DNO was subsequently extended to cases with complete or incomplete recovery after the first attack (monophasic DNO) and with a relapsing course (r-DNO), raising the question whether DNO represents a distinctive form or a variant of multiple sclerosis (MS) [1-3]. According to the diagnostic criteria which have been derived by Wingerchuk et al. [1], diagnosis of DNO can be applied to patients satisfying all the three absolute criteria (occurrence of $\mathrm{ON}$, occurrence of acute myelitis, no evidence of clinical central nervous system involvement apart from the optic nerve and spinal cord) and one major supportive criteria (negative brain magnetic resonance imaging (MRI) at onset, spinal cord signal abnormality extending over three vertebral segments, cerebrospinal fluid (CSF) pleocytosis of $>50 \mathrm{WBC} / \mathrm{mm}^{3}$ ) or two minor supportive criteria (bilateral $\mathrm{ON}$, severe $\mathrm{ON}$, severe myelitis). A negative brain MRI is accepted as mandatory and not only 'supportive' by some authors in the diagnosis of DNO [4]. On the contrary, spinal cord MRI shows that the affected regions of the cord, which usually extend over three or more vertebral segments are swollen and may enhance after gadolinium administration during the acute phase. After the acute episode, persistent intramedullary $\mathrm{T}_{2}$ signal abnormalities and/or cord atrophy are usually detected [5]. CSF examination revealing rel- evant pleocytosis is a major supportive criteria. Oligoclonal bands (OBs) have been reported in $22.7 \%$ of patients. Similar to MS, OBs may appear during the course of the disease but at variance with MS, they may also disappear [6]. Most authors believe that these features support the concept that DNO is a separate syndrome [7-10]. Compared with MS, DNO affects more frequently females, subjects of an older age, and leads to more severe neurological impairment [1,3]. Demyelination and cavitation of optic nerves and spinal cord, necrosis of both gray and white matter, lack of inflammatory infiltrate, vascular hyalinization and fibrosis are the most relevant pathological findings [11].

DNO can be associated with autoimmune diseases such as systemic lupus erythamatosus, Sjögren syndrome and autoimmune thyroiditis [8-10, 12, 13]. Detection of autoantibodies (antithyroid, antiDNA, anticardiolipin) is frequent [8-10]. However, there is only one case report about DNO associated with a mitochondrial DNA mutation [14]. We herein report the second case with r-DNO and concomitant mutation of mitochondrial DNA.

\section{Case Report}

A 24-year-old female, with negative family history and no relevant previous diseases, presented with an acute attack of right-sided painless vision loss. Though she was given corticosteroid therapy, there was no significant improvement. As she was admitted and treated in another hospital the rest of the medical data could not be gathered.

Four years later at the age of 28 , she developed left-sided painless vision loss and was admitted to our hospital. She was given intravenous methylprednisolone but the vision did not improve. Her cranial MRI was normal. Two years later, at the age of 30, she developed 2 more attacks of visual loss in her left eye and her final visions were at the level of finger counting from $30 \mathrm{~cm}$ on the left side and at the level of light perception on the right side with bilateral optic atrophy. She was tested for mutations of mitochondrial DNA and two homoplasmic secondary mutations at nucleotide positions 4216 and 4917 were detected.

At the age of 31 , she presented with weakness of her legs and urinary dysfunction. On examination, she was paraparetic with a sensory level at $\mathrm{C}_{4}$. Her second cranial MRI was again normal; however, the spinal MRI showed a $T_{2}$ hyperintense lesion enlarging the cord, which extended from $\mathrm{C}_{4}$ to $\mathrm{T}_{4}$ level (fig. 1). She had never experienced any oral aphthous lesions, genital ulcerations or skin lesions compatible with Behçet's disease, and the slit lamp examination performed in the ophthalmology clinic did not reveal any findings consistent with uveitis. Immunologic tests including antinuclear antibody, ethanol and formalin ANCA, anti-Ro, anti-La antibodies, antidsDNA, anticardiolipin IgM and anticardiolipin $\mathrm{IgG}$ levels did not reveal any pathology as well as the serologic tests for Lyme and Treponema. Examination of the

\section{KARGER}

Fax +4161306 1234 E-Mail karger@karger.ch www.karger.com
C 2006 S. Karger AG, Basel 0014-3022/06/0552-0093\$23.50/0

Accessible online at: www.karger.com/ene
Neşe Celebisoy, MD

Ege University Medical School

Department of Neurology

Bornova, TR-35100 İzmir (Turkey)

Tel. +90232390 3824,Fax +90 232388 0980,E-Mail nese.celebisoy@ege.edu.tr 


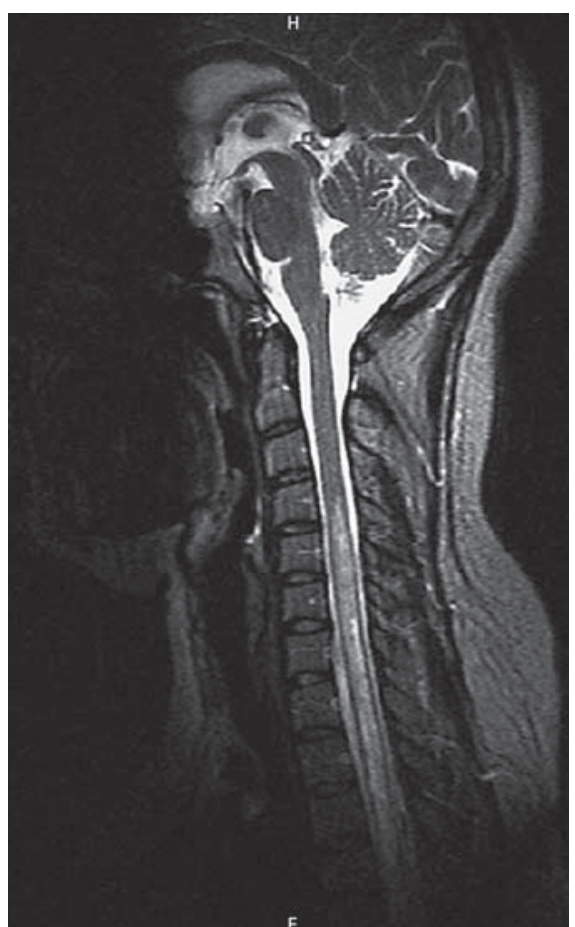

Fig. 1. $\mathrm{T}_{2}$-weighted sagittal MRI of the cervical spine showing a $T_{2}$ hyperintense lesion enlarging the spinal cord, which extended from $\mathrm{C}_{4}$ to $\mathrm{T}_{4}$ level.

CSF showed high total protein content $(95 \mathrm{mg} / \mathrm{dl})$ and pleocytosis $(110 \mathrm{WBC} /$ $\mathrm{mm}^{3}$ ). OBs were not present. She was given intravenous methylprednisolone and responded well. At the end of 2 months she was able to walk without support. At the age of 33, she developed two more attacks together with weakness of the lower limbs more prominent on the right side and urinary dysfunction. She was again treated with methylprednisolone and showed good recovery and she was able to walk independently. Spinal MRI performed 1 year after these attacks showed atrophy of the thoracic segments of the spinal cord. The patient asked her two sons to undergo mitochondrial DNA analysis and the same mutations were found in both of them.

\section{Discussion}

Our patient was diagnosed as r-DNO according to the diagnostic criteria established by Wingerchuk et al. [1]. She had four attacks of ON and three attacks of myelitis. Her brain MRI was normal. Spinal MRI performed during the first myelitis attack revealed a long segment spinal lesion. Her last spinal MRI showed atrophy of the previously involved cord segments. There are two large studies about the clinical characteristics of DNO: the North-American study [8] included 80 patients (23 monophasic and 57 relapsing), and the Italian study [10] included 46 r-DNO patients. Relapsing forms, which are more frequent $(70 \%)$ than the monophasic forms, are reported to be more common in women $(80 \%)$, and the age of onset is older. They are more often associated with autoimmune diseases $[8,10]$. However, an association with a mitochondrial DNA mutation has been reported in only one case [14]. No studies searching for mitochondrial DNA mutations in patients with DNO could be found in the literature.

Mitochondrial DNA mutations predisposing to MS are still a matter of debate. Harding et al. [15] were first to describe the association of mutation 11778 , a primary Leber's hereditary optic neuropathy (LHON) mutation, and an MS-like picture. Several other patients with primary LHON mutations and an MS-like disease have subsequently been reported [16-20]. A higher frequency of secondary mutations in MS patients has also been detected [21, 22]. However, no clues are available on how the mitochondrial defects lead to an immunemediated disease. There are also reports about MS patients in whom primary mutations could not be found and the frequency of the secondary mutations was similar to that of controls [23-25].

There is only one Italian report of a patient with DNO who had concomitant mitochondrial DNA mutation at nucleotide position 3460 , which is a primary mutation. Our patient is the second case, with two homoplasmic secondary mutations at nucleotide positions 4216 and 4917. These mutations were detected after her $\mathrm{ON}$ attacks before the attacks of myelitis had developed. The mutations 4216 and 4917 are considered secondary/intermediate mutations. They are homoplasmic and are associated with each other and with primary mutations. They are also observed in control populations, although at a lower frequency than in LHON populations, and appear to be more common in Europeans or in subjects of European ancestry than in other populations [26]. It is not easy to say that there is a predisposing effect of mitochondrial DNA mutations in DNO based on just two cases, but the hypothesis is interesting and deserves further investigation on patient groups with this disease.

\section{References}

1 Wingerchuk DM, Hogancamp WF, O'Brien PC, Weinshenker BG: The clinical course of neuromyelitis optica (Devic's syndrome). Neurology 1999;53:1107-1114.

2 Pambakian A, Akdal G, Kennard C: Neuromyelitis optica (Devic's disease) and its relationship to MS. Int Mult Scler 2000;6:91-95.

3 Weinshenker BG: Neuromyelitis optica: what it is and what it might be. Lancet 2003;361: 889-890.

4 Bergamaschi R, Ghezzi A: Devic's neuromyelitis optica: clinical features and prognostic factors. Neurol Sci 2004;25:S364-S367.

5 Filippi M, Rocca MA: MR imaging of Devic's neuromyelitis optica. Neurol Sci 2004;25: S371-S373.

6 Zaffaroni M, the Italian Devic's Study Group: Cerebrospinal fluid findings in Devic's neuromyelitis optica. Neurol Sci 2004;25:S368S370.

7 Fazekas F, Offenbacher H, Schmidt R, Strasser-Fuchs S: MRI of neuromyelitis optica. Evidence for a distinct entity. J Neurol Neurosurg Psychiatry 1994;57:1140-1142.

8 Wingerchuk DM, Weinshenker BG: Neuromyelitis optica. Clinical predictors of a relapsing course and survival. Neurology 2003;60: 848-853.

9 Bergamaschi R, Ghezzi A: Devic's neuromyelitis optica: clinical features and prognostic factors. Neurol Sci 2004;25:S364-S367.

10 Ghezzi A, Bergamaschi R, Martinelli V, Trojano M, Tola MR, Merelli E, Mancardi L, Gallo P, Filippi M, Zaffaroni M, Comi G and the Italian Devic's Study Group: Clinical characteristics, course and prognosis of relapsing Devic's neuromyelitis optica. J Neurol 2004;251: $47-52$.

11 Mandler RN, Davis LE, Jeffery DR, Kornfeld M: Devic's neuromyelitis optica: a clinicopathological study of 8 patients. Ann Neurol 1993; 34:162-168.

12 Giorgi D, Balacco Gabriel C, Bonomo L: The association of optic neuropathy with transverse myelitis with systemic lupus erythamatosus. Rheumatology 1999;32:191-192.

13 Tesar JT, Mc Millan V, Molina R, Armstrong $\mathrm{J}$ : Optic neuropathy and central nervous system disease associated with Sjögren's syndrome. Am J Med 1992;92:686-692.

14 Ghezzi A, Baldini S, Zaffaroni M, Leoni G, Koudriavtseva T, Casini AR, Zeviani M: Devic's neuromyelitis optica and mitochondrial DNA mutation: a case report. Neurol Sci 2004; 25:S380-S382.

15 Harding AE, Sweeney MG, Miller DH, Mumford CJ, Kellar-Wood H, Menard D, McDonald WI, Compston DAS: Occurrence of a multiple sclerosis-like illness in women who have a Leber's hereditary optic neuropathy mitochondrial DNA mutation. Brain 1992;115: 979-989.

16 Flanigan KM, Johns DR: Association of the 11778 mitochondrial DNA mutation and demyelinating disease. Neurology 1993;3:27202722. 
17 Kellar-Wood H, Robertson N, Govan GG, Compston DAS, Harding AE: Leber's hereditary optic neuropathy mitochondrial DNA mutations in multiple sclerosis. Ann Neurol 1994;36:109-112.

18 Carrara F, Eoli M, La Mantina L, Zeviani M: The contribution of LHON mitochondrial DNA muations to multiple sclerosis. Am J Hum Genet 1995;57:A336.

19 Leuzzi V, Carducci C, Lanza M, Salvetti M, Ristori G, Di Giovanni S, Torroni A: LHON mutations in Italian patients affected by multiple sclerosis. Acta Neurol Scand 1997;96: 145-148.
20 Vanopdenbosch L, Dubois B, D’Hooghe MB, Meire F, Carton H: Mitochondrial mutations of Leber's hereditary optic neuropathy: a risk factor for multiple sclerosis. J Neurol 2000; 247:535-543.

21 Chalmers RM, Robertson N, Compston DAS, Harding AE: Sequence of mitochondrial DNA in patients with multiple sclerosis. Ann Neurol 1996;40:239-243.

22 Kalman B, Lublin FD, Adler H: Characterization of the mitochondrial DNA in patients with multiple sclerosis. J Neurol Sci 1996;140:7589 .

23 Franciotta D, Bergamaschi R, Piccolo G, Zardini E, Cosi V: Multiple secondary Leber's hereditary optic neuropathy mutations in Italian patients with multiple sclerosis. J Neurol 2000; 247:304-305.
24 Hwang JM, Chang BL, Park SS: Leber's hereditary optic neuropathy mutations in Korean patients with multiple sclerosis. Ophthalmology 2001;215:398-400.

25 Penisson-Besnier I, Moreau C, Jacques C, Roger JC, Dubas F, Revnier P: Multiple sclerosis and Leber's hereditary optic neuropathy mitochondrial DNA mutations. Rev Neurol 2001; 157:537-541.

26 Torroni A, Petrozzi M, D’Urbano L, Sellitto D, Zeviani M, Carrara F, Carducci C, Leuzzi V, Carelli V, Barboni P, De Negri A, Scozzari R: Haplotype and phylogenetic analysis suggest that one European-specific mtDNA background plays a role in the expression of the primary mutations 11778 and 14484. Am J Hum Genet 1997;60:1107-1121. 